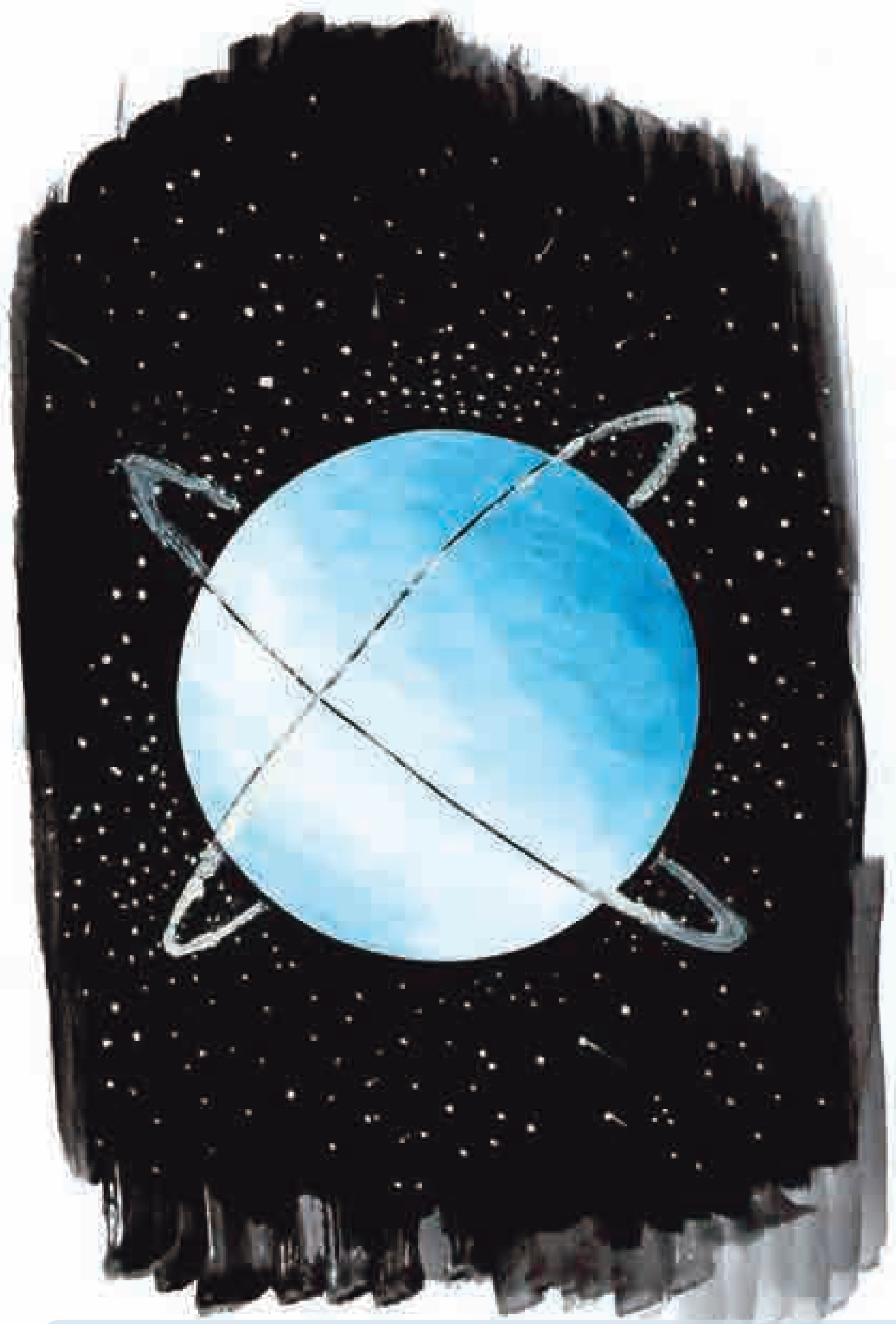

Ilustración 9. Los frailes dominicos realizaron sus labores habituales, Rubén Darío revisó el orden del día del próximo Consejo Directivo, Luis Eduardo adelantó los preparativos para El Día de la Colombianidad y Carlos Ariel revisó el estado financiero. 



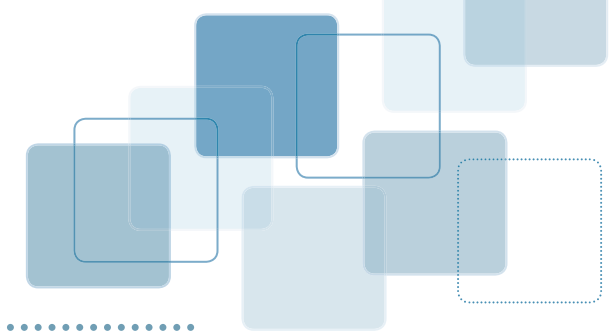

\section{EL TRANCÓN DE LA AUTOPISTA NORTE}

El día amaneció lluvioso. Pronto los rayos del sol se abrieron paso entre los cerros Orientales, el frío cedió y el día logró esplendor y calidez. Los frailes dominicos realizaron sus labores habituales, Rubén Darío revisó el orden del día del próximo Consejo Directivo, Luis Eduardo adelantó los preparativos para el Día de la Colombianidad y Carlos Ariel revisó el estado financiero. A las 10:00 a.m. tomaron las onces y hablaron de algunos pormenores de la vida escolar.

—AA la 1:30 nos vemos en el parqueadero! —dijo Luis Eduardo.

— ¡Bien! —musitó Carlos Ariel. Rubén Darío también asintió con la cabeza. Después se encerraron en sus actividades. Tiempo después se vieron en el sitio acordado y emprendieron la marcha. En la Autopista Norte el represamiento vehicular era insoportable.

— ¿Qué pasó? —preguntó Rubén Darío cuando constató que el flujo de los vehículos se hizo lento.

— ¡Seguramente es un accidente! — dijo Carlos Ariel. Minutos más tarde pasaron frente a un vehículo averiado. 
-Una falla mecánica es habitual, pero vararse en la Autopista Norte es muy cotidiano - agregó Luis Eduardo y arrancó grandes risotadas en sus hermanos. Lentamente salieron del trancón, el resto del camino no hubo mayores sobresaltos vehiculares. Minutos más tarde llegaron a Teusaquillo, guardaron el vehículo en un parqueadero aledaño y buscaron el lugar.

— ¡Aquí es! —dijo entusiasmado Rubén Darío, luego de caminar algunas calles.

— ¡Corpovisionarios! —dijo Luis Eduardo, después de leer el anuncio en una de las paredes del lugar. Era una casa grande, de dos plantas, sus pisos cubiertos por una madera crujiente los devolvió en el tiempo a los años cuarenta. Ascendieron por una vieja escalera, se anunciaron en la recepción, tiempo después los condujeron a una pequeña salita. Las cuatro paredes del lugar estaban engalanadas con un número indeterminado de pequeños cuadros con marcos de madera, en el que reposaban igual número de caricaturas de Antanas Mockus, unas en color y otras en carboncillo, encerradas detrás de un delicado vidrio transparente. Los frailes se sentaron alrededor de una mesa circular, a esperar al doctor Mockus.

-Buenos días - dijo una voz dulce.

-Buenos días - respondieron los frailes en coro. La voz era la de Antanas Mockus, saludó a los dominicos con un suave apretón de manos. No era un hombre muy alto pero inspiraba tranquilidad, sus ojos profundamente azules daban la sensación de estar frente a un detective de novelas policíacas.

—Doctor Mockus, somos frailes dominicos, yo soy Rubén Darío López, rector, las personas que me acompañan son Luis Eduardo Pérez, vicerrector y Carlos Ariel Betancourth, síndico del Colegio Santo Tomás de Aquino.

—Bienvenidos a Corpovisionarios ¿Qué los trae aquí? - dijo el profesor Mockus. 
-Dos cosas — se apresuró Carlos Ariel. La primera invitarlo a participar en un foro educativo que realizaremos el 15 de febrero de 2013. La segunda, solicitarle el favor que nos conceda una entrevista.

— ¿Claro que sí! —dijo Antanas. ¿Para qué es la entrevista?

-Es una de las estrategias metodológicas que hemos diseñado para nuestro trabajo de investigación - afirmó Luis Eduardo. Los tres realizamos Maestría en Educación, nuestro tema de investigación es lo cotidiano.

—Adelante —dijo Mockus.

—Doctor, Mockus ¿Por qué hablar de lo cotidiano en la escuela? inquirió Carlos Ariel sin mayor preámbulo.

-Para saber-hacer las cosas, nos sirve también un cierto "saber por qué". Pero hay una pregunta sobre todo por "el para qué" que ayuda a poner en su sitio las competencias y las explicaciones -afirmó Antanas. Es bonito tener capacidades que ofrecer en la vida, ser útil a los proyectos colectivos como aspectos de otras personas. Yo detestaba, como maestro, la impuntualidad de los estudiantes. Entonces, hice los diez primeros minutos de cada clase lo más interesante posible. Así que traía poemas, traía literatura, traía discusiones de actualidad, eso hizo que los estudiantes llegaran puntualmente a mis clases. "lo actual" fue el dispositivo que encontré para hacerlos madrugar. "lo actual" es lo cotidiano y todos se sienten atraídos por lo cotidiano. La escuela no puede descuidarlo.

—Perdón ¿se les ofrece algo? —interrumpió una mujer. Los cuatro ordenaron una taza de café, la mujer no tardó con el pedido y desapareció por completo.

Hoy mis estudiantes, profesionales muchos de ellos, se acuerdan más de los diez minutos que de la clase misma. El mensaje sí lo relaciono muy fuertemente con lo cotidiano, pues esta estrategia era como buscar el polo extremo, opuesto, al estudiante que le dice a uno: ¡esto no tiene sentido! Me acuerdo, por ejemplo, que hablaba y discutía con los estudiantes que 
habitaban las residencias universitarias de la Universidad Nacional durante los primeros diez minutos de los que les he hablado-. Un día les dije: "Ustedes quieren tener las residencias universitarias con otros fines... Para meterse con sus novias", con eso avivaba mis clases porque para ellos era asombroso que un profesor les hablara de un tema como este.

— ¿Por qué se presentaba tal situación? — dijo emocionado Rubén Darío.

- La gente podía llevar armas a la residencias, pues las residencias cambiaban de sentido, era como explicarles: "la universidad va a cerrar esas residencias si ustedes se las ponen de ruana o no respetan las reglas". Era invitarlos, o acercarlos a las categorías que íbamos a usar en las clases, como por ejemplo, ley, moral, cultura y el divorcio entre ley y cultura. Es decir, trabajábamos desde sus experiencias comunes. Incluso, alguna vez, tuve la vertiginosa sensación que eso se parecía a una confesión, era una experiencia intensa para los estudiantes, revisaban sus vivencias en términos de lo que estábamos analizando en el curso.

-Doctor, Mockus ¿se puede enseñar el saber racional desde lo cotidiano? — dijo Luis Eduardo.

- Yo enseñé mucho tiempo en la Facultad de Ciencias Humanas de la Universidad Nacional. Me acuerdo de un estudiante, Carlos Araque, teatrero, desde la primera clase de matemáticas -en la Nacional no es posible graduarse de antropólogo, por ejemplo, sin haber tomado un curso de matemáticas- me bloqueó. Reiteradamente, me preguntaba ¿Por qué tengo que estudiar yo como antropólogo matemáticas? Meses después escribió una obra de teatro donde él y su sombra discuten si él puede o no puede, debe o no debe aprender matemáticas. Y al final del semestre era el más preguntón por la nota, sobre cómo le fue en el curso de matemáticas. Digamos, ese es un caso particular en el que a partir de una reacción defensiva se logra cómo suscitar el interés. En este caso, el teatro representa lo extrovertido-trágico, es como La nús ea de Sartre.

—¿Cuál es el papel del lenguaje en lo cotidiano? —inquirió Carlos Ariel. 
- Hay un autor, Vasili Kandinski, quien tuvo un alumno en Colombia, Mario Díaz. Díaz trabajó en Cali, precisamente en la Universidad del Valle, durante mucho tiempo. Mario Díaz se doctoró con Kandinski, este último, de algún modo, lo que plantea es sumamente simple: uno cuando aprende una lengua, aprende a decir todo lo que en esa lengua se podría decir, digamos potencialmente, uno adquiere todo lo que el castellano nos ofrece y no nos es ajeno. Lo que está planteando Kandinski es que uno nunca aprende un idioma sin tener un "otro sociológicamente determinado", es decir, nadie es criado por la mujer y el hombre en abstracto, todos hemos sido criados por un padre y por una madre, por un acudiente, por un hermano específico, que al mismo tiempo nos enseñaron el lenguaje y los límites que este nos impone.

Entonces, uno como que adquiere todas las herramientas del lenguaje -dijo e hizo una pausa profunda-, pero al mismo tiempo adquiere, como las férulas que le colocan a uno cuando nos rompemos un hueso, limitaciones. Es decir, uno adquiere el lenguaje con restricciones, el lenguaje mismo acuña la expresión códigos restringidos -es un poco cruel- versus códigos elabr ados y de algún modo desde él se ve que no es tan fácil partir de lo cotidiano para enseñar. Es decir, de algún modo hay niños que por su familia adquieren como las dos orientaciones: pasan a hablar de la comida en el lenguaje común y corriente y hablan de la comida en lenguaje de carbohidratos y vitaminas y proteínas. En cambio, otros niños que les cuesta mucho trabajo hablar de algún modo de lo que no se ve. Para mucha gente el portador de los códigos elaborados es la iglesia, es la comunidad religiosa, ese es un canal. Otro canal puede ser en algunos casos extremos, las organizaciones políticas. Yo conocí en el sur de Santander un pueblito donde la gente estaba sobreeducada, pues preparaban las conferencias de una manera asombrosa, los adolescentes leían revistas científicas dirigidas a la formación profesional y lo hacían para interrogarme. Yo me preguntaba ¿estos niños, de catorce y quince años, cómo pueden ser tan lúcidos?

— ¿Qué acontecimientos de la vida cotidiana de la escuela podríamos usar para mejorar nuestra práctica educativa? — dijo Rubén. 
—No sé. Me parece que una de las innovaciones educativas que admiro mucho y muy elemental, es un cuaderno que se llamaba Mi proyecto de vida. Este estaba estructurado con la sugerencia de que lo que te pasa el día a día, hora tras hora, tiene relevancia de cara a tu proyecto de vida. Digamos, las primeras páginas, el joven era invitado a escribir su proyecto de vida y después a llevar un diario. En esas aulas, había innovación. Conozco gente que a los 16-17 años vive en función de lo que ha escrito, es decir, filtra sus experiencias con la mirada. Sartre, por ejemplo, salía a los Campos Elíseos con unas marionetas, una vez descrestó a una muchacha que se quedó perpleja mirando la obra de teatro que él logró realizar con sus títeres. Desde luego, Sartre se goza la obra de teatro, se goza la mirada de la señorita, pero más que esas dos cosas, se goza la manera en que va a escribir cuando regrese a su apartamento. Entonces, lo que gana en autonomía un ser humano, sí se puede escribir.

—Doctor, Mockus ¿cómo enseñar a los estudiantes a pensar en su sexualidad? —dijo Luis Eduardo.

—La sexualidad es un territorio clave para los jóvenes. Yo le creo un poco a Foucault en su tesis, lo voy a formular de manera un poco sarcástica: el catolicismo ayudó a hacer el sexo interesante, se volvió un terreno de disputa entre el bien y el mal, en vez de ser un tema de pura salud pública como sería la tendencia actual. Una vez le dije a un sacerdote que confesaba en Monserrate, Sin violar el secreto de confesión ¿puede hacer usted un resumen de las confesiones sexuales de los feligreses? El hombre me contestó de una manera muy bella: "yo trato de transformar la culpa sexual en culpa social". Me pareció como el mejor resumen del Concilio Vaticano II.

— ¿Qué entiende Antanas Mockus por lo cotidiano? —dijo Carlos Ariel.

- Sí. Hay días marcados por celebraciones, marcados por actividades especiales para ese día que serían lo contrario de un día cualquiera dijo Antanas. Lo cotidiano sería lo que pertenece fundamentalmente a los días cualesquiera, al día que no lleva ninguna marca especial. Ahora, sí uno mira con detenimiento, cada día es especial, cada día tiene su 
santo y su santa, cada día le puede pasar a uno algo extraordinario. Al principio no había días ordinarios -pienso en el Libro del Génesis-, tal vez con la echada del Paraíso, seis de los siete días se volvieron ordinarios. Tal vez el día ordinario es el día del trabajo, es el día del sudor, es el día de las lágrimas. Digamos, lo cotidiano funcionaría en oposición a lo sagrado, es decir, uno tendería a decir que en los días corrientes suceden acontecimientos corrientes.

Ahora, alguna gente logra vivir todos los días como si fueran días sagrados. Para mí, por ejemplo, el domingo es el día más luminoso: tuve un amigo que los domingos me invitaba a oír música y bebíamos coca-cola en cantidades exageradas, eso hacía parte de la celebración. Mis padres se vestían más elegantes los domingos, por el tema de la misa. En general, íbamos a una misa de lituanos, como de ciento veinte lituanos. Una de las cosas más terribles que aprendí allí fue la jerarquía social de la colonia, cuando mi papá llegaba saludaba primero al cura, al sacerdote, que era también profesor universitario, después saludaba al hombre más rico, luego a los dos o tres académicos que habían y por allá de últimas a un almacenista que era el papá de una muchacha muy linda. Durante muchos años mi vida estuvo marcada por el ritmo semanal, la diferencia la hacía el domingo, incluso la comida era un poco mejor. El catolicismo del norte, Lituania es súper católica. Por andar leyendo esas cosas de estudios de valores descubrí que Lituania está supremamente secularizada y yo tenía la convicción de que los lituanos eran, igual que los polacos, casi que católicos fanáticos, y no, por lo menos en los estudios más recientes el único valor que sobrevive es el del trabajo, de los valores clásicos. Lituania tiene la tasa de suicidios más alta del mundo hoy en día, o sea, en Colombia por 5 suicidios hay 35 homicidios, o sea por un suicidio hay siete homicidios. En Lituania es al contrario, por un homicidio hay siete suicidios, sumando ambas cosas empatan, pero lo uno es violencia contra sí, lo otro es violencia hacia el otro.

— ¿Por qué la escuela tiene que hablar de lo cotidiano? —dijo Rubén. - ¡Para no excluir! Es decir, a unos jóvenes, a unos niños desde su hogar están acostumbrados a un lenguaje en que remitía realidades muy concretas, muy vividas, como muy intensamente y escritas en un lenguaje muy directo $\mathrm{y}$, además, un lenguaje donde la componente 
verbal no se aísla de los demás componentes. El niño de clase media o de clase alta aprende como a verbalizar más, a dar menos por supuestas las experiencias compartidas. Entonces, los códigos restringidos son supremamente eficaces y en la vida común y corriente sirven mucho para no ser redundantes, para no repetir. Pero en la vida académica el componente verbal es muy importante que sea autónomo. Un niño de clase media-alta cuando se le muestra algunas imágenes, él junta, concatena las láminas, arma una historia.

Ahora bien, ver la organización de las sociedades de África del Sur es pavoroso. Aquí están las negritudes, aquí los colorados, aquí los blancos, y es paradójicamente, el centro de la ciudades donde se mezcla de resto de la gente que vive claramente segregada. Pero hoy en día la mayor exclusión se presenta en las matemáticas, entre otras cosas, porque la gente termina atribuyéndole a esta ciencia sus fracasos personales. Yo fui muy exitoso escolarmente, en parte porque mi papá se compró una aritmética de Baldor cuando yo tenía siete años y durante unas vacaciones decidió él adelantarme por medio año. Todos los días por la mañana antes de salir me ponía la tarea y todos los días al final del día me la recogía. Entonces, yo crecí un poco con la ideología del súper talento y el chino genio, pero cualquier papá que le hubiera dedicado esas horas, o ese grado de compromiso a su hijo, probablemente, hubiera producido hijos sobrados en matemáticas. Él mismo era autodidacta y su disciplina era excepcional, incluso aprendió inglés a partir de un libro, sin disquete ni discos, lo hizo con la pura transliteración. Se consiguió un amigo que enseñaba latín y griego, que le hizo el favor de traducir la anotación fonética. Después, él mismo leía las cosas como se pronunciaban en inglés y estudió ingeniería por correspondencia. Cuando murió, a los 44 años, era jefe de diseño de la empresa metalmecánica más grande que había en el país.

-Entonces ¿enseñar desde lo cotidiano también es una forma de inclusión? —dijo fascinado Luis Eduardo.

-Decir que así como hay exclusión hay también una especie de inclusión educativa, es una especie de premio inesperado para el que confía en los educadores. Yo entré un año adelantado y era el chiquito 
del curso, entonces me pegaban, eso también me dio ventajas porque muy rápido aprendí en la vida a defenderme con palabras y no a puños. Si era a puños perdía. Yo creo que muchos aprendemos en el colegio, pero también en la cuadra, también en el edificio. Alguna vez terminé en la Iglesia Santa Ana llorando porque discriminé a una muchacha, entonces fue un acto mío de discriminación social horrible, apenas me di cuenta de eso me metí en la iglesia a llorar como arrepentido.

Mirándolo bien, a un niño es muy difícil explicarle las normas de desigualdad que hay en la sociedad colombiana, pues mis padres lograron inculcarnos "aquí no hay muebles, aquí no hay electrodomésticos pero hay libros". La primera comunión de la hija del jefe de mi papá fue con fiesta en el Club Militar, pues hoy en día miro al Club Militar sin demasiada fantasía, sin demasiado antojo pero cuando yo era niño era impresionante.

Finalmente, los frailes agradecieron la amabilidad del profesor Mockus, él se comprometió a asistir al foro educativo que los dominicos estaban organizando. 
